\title{
LA IDENTIDAD AFROPANAMEÑA EN LA LITERATURA DESDE EL SIGLO XX HASTA EL NUEVO MILENIO
}

\author{
Afro-Panamanian Identity in the Literature from the Twentieth to the New Millennium \\ Sonja Stephenson Watson
}

Resumen: La identidad negra en Panamá es un concepto complejo y problemático por la coexistencia de dos grupos de negros en el país: los afrocoloniales y los afroantillanos. Mientras que los afrocoloniales son producto del mestizaje racial y se identifican por su nacionalidad panameña, los afroantillanos son inmigrantes y siguen el modelo racial de sus países natales —Jamaica y Barbados — que se basa en la negritud. Por ende, se identifican como negros. Por eso, en Panamá es difícil hablar de una identidad afropanameña por la fluidezy la hibridez racial, cultural y lingüistica. Los escritores afropanameños Juan Urriola, Gaspar Octavio Hernández Carlos Cubena Guillermo Wilson y Melva Lowe de Goodin representan a estos dos grupos étnicos. Por consiguiente, en sus obras se manifiesta la problemática de la identidad, que es un reflejo de la diáspora africana.

Palabras clave: afropanameñidad, afroantillanos, afrocoloniales, Canal de Panamá, identidad nacional.

Abstract: Black Panamanian identity in Panama is both complex and problematic becauseof the coexistence of two groups of blacks in the country: afro-colonials and black West Indians. While afro-colonials are the product of race mixing and identify by their Panamanian nationality, West Indians are immigrants and follow the racial model of their native countries-Jamaica and Barbados- which are racially constructed around blackness. Therefore, they identify as black. As a result, in Panama it is difficult to talk about Afro-Panamanian identity because it is marked by fluidity and racial, cultural and linguistic hybridity. The afro-Panamanian writers, Juan Urriola, Gaspar Octavio Hernández Carlos Cubena Guillermo Wilson, and Melva Lowe de Goodin represent these two ethnic groups. As a result, their works manifest the problematic of identity which is a reflection of the African diaspora.

Keywords: Afro-Panamanian, West Indian, afro-colonial, Panama Canal, national identity.

Sonja Stephenson Watson, doctora en Literatura Hispánica por la Universidad de Tennessee-Knoxville, Estados Unidos. Profesora de español asociada y directora del Women's and Gender Studies Program, de la Universidad de Texas en Arlington, Estados Unidos. Temas de especialización: literatura afropanameña, literatura en español del Caribe y reggae en español. Correo electrónico: swatsonl@uta.edu.

Enviado a dictamen: 23 de junio de 2014 Aprobación: 3 de marzo de 2015.

Revisiones: 2 . 
E año 2014 fue seminal en la historia de Panamá. En ese año, el país abrió la primera línea del sistema de metro en el istmo que atraviesa la ciudad de Panamá. 2014 también marcó la celebración del centenario de la construcción del Canal de Panamá (1904-1914), proyecto arduo iniciado por la visión de Francia (1880-1889) y llevado a su culminación por Estados Unidos (1904-1914) con la mano de obra de más de cien mil inmigrantes afroantillanos del Caribe anglófono. ${ }^{l}$ Esta celebración no es únicamente importante para la historia de Panamá por sus relaciones con Estados Unidos, sino también por la llegada de miles de inmigrantes afroantillanos procedentes de Jamaica y Barbados para construir el canal. Los afroantillanos alteraron para siempre la estructura poblacional y el concepto de raza y nación en un país de habla española que se negaba a reconocer la presencia de raíces africanas, lo que lo había caracterizado desde la llegada de los primeros negros durante el siglo XVI.

La identidad negra en Panamá es un concepto complejo y problemático por la coexistencia de dos grupos de negros en el país: los afrocoloniales y los afroantillanos. El primer grupo, los afrocoloniales, es el producto del mestizaje racial y sus integrantes se identifican por su nacionalidad, es decir, como panameños. El segundo, los antillanos, son inmigrantes y siguen el modelo racial de sus países natales - Jamaica y Barbados-. Por ende, se identifican como negros. Estos dos grupos étnicos en Panamá nos recuerdan que la identidad diaspórica se caracteriza por la hibridez, la diversidad y la diferencia, según el crítico cultural Stuart Hall. La teoría de Hall será usada en este análisis para explorar la compleja identidad de los afrodescendientes en Panamá y, por ende, la diáspora africana.

Según Hall, la identidad de un individuo se concibe por sus semejanzas y diferencias. El concepto de identidad que se basa en las semejanzas - cultura, lengua, raza - no toma en cuenta las diferencias raciales, lingüísticas y culturales que caracterizan a los miembros de la diáspora africana. La conceptualización de la identidad que se basa en sus semejanzas resulta en una articulación artificial que no cubre la totalidad del individuo, comunidad o región. Hay otra manera de entender la identidad según Hall: a través de las diferencias. Y es precisamente a través de estas diferencias como las comunidades diaspóricas afroamericanas pueden ser identificadas por sus distinciones raciales, culturales y lingüísticas.

La teoría de Hall nos permite hacer una evaluación crítica de la problemática de la identidad afropanameña pasada y contemporánea porque se trata de una identidad marcada por la diversidad e hibridez. En "Cultural Identity and Diaspora", Hall señala que las identidades diaspóricas se transforman para producir nuevas identidades caracterizadas por la multiplicidad racial, cultural y lingüística (Hall, 1989: 235). Con respecto a la formación de la identidad, Hall reconoce que las identidades están en proceso y se caracterizan por la diferencia. De hecho, la identidad es un proceso que se transforma para producir otras características marcadas por la fluidez y la hibridez. Esta hibridez marca la identidad de los afrodescendientes en Panamá y sigue impidiendo la unión de estos dos grupos étnicos a pesar de que comparten una herencia común: África.

La identidad negra en Panamá es compleja, pero también es un reflejo de la experiencia vivencial diaspórica africana. Esta complejidad se manifiesta en la literatura escrita por los descendientes africanos en el país. La literatura de los afropanameños del siglo XIX hasta el presente refleja esta diversidad y la problemática de la identidad afrolatinoamericana. Más que nada, muestra los desafíos de los descendientes africanos en Panamá para identificarse como negros, caribeños y panameños, en un país que únicamente desea celebrar sus raíces hispanas. Además, subraya las tensiones intraétnicas — ambas reales e imaginariasentre los afrocoloniales y los afroantillanos, que han impedido el desarrollo de una identidad afropanameña unificada.

La literatura de los descendientes africanos en Panamá ilustra que la trayectoria de esta unión se caracterizó por tensiones intraétnicas, así como por las políticas raciales y culturales conformadas por las ideologías del mestizaje y la negritud. La literatura negra en Panamá se divide en dos categorías: la literatura escrita por los afrocoloniales y la de los antillanos que 
son parte de la comunidad que emigró principalmente del Caribe británico - Jamaica y Barbados - para trabajar en el ferrocarril transístmico (1850-1855) y en el canal (1904-1914). Mientras que los afrocoloniales se asimilaron, las primeras generaciones de inmigrantes antillanos nacidos en Panamá - los que nacieron antes de 1945- no lo hicieron y siguen afirmando su conciencia negra sobre su nacionalidad panameña. Este conflicto ha causado tensiones en las relaciones raciales entre los antillanos y panameños porque el primer grupo desafía una nacionalidad panameña que se basa en la hispanidad. Después de su independencia de Colombia en 1903 con la ayuda de Estados Unidos, los panameños querían mostrar su filiación cultural con España. Como Estados Unidos controlaba la construcción del canal y tenía una presencia fuerte en el istmo, sobre todo en la zona que se ubica entre las ciudades terminales de Panamá y Colón, los intelectuales panameños pensaban que era necesario recalcar sus raíces hispanas. Durante la época de postindependencia (1903-1940), la oligarquía panameña reforzaba la hispanidad frente al imperialismo norteamericano, que constituía una presencia vigente en la zona.

El enfoque nacional en las raíces hispanas sobre las raíces étnicas afectó la manera en que los grupos étnicos se identificaron. Mientras que los afrocoloniales promovieron su filiación cultural y nacional con el pais, los afroantillanos rechazaron los tres dogmas nacionales - cultura, lengua y religión-, ya que eran de color negro, de habla inglesa y protestantes. Las diferencias culturales y lingüísticas entre los afrocoloniales y los afroantillanos, y la discriminación nacional abierta dirigida a este último grupo, dividieron a las dos poblaciones de acuerdo con sus diferencias culturales y lingüísticas, a pesar de su herencia africana común. Por lo tanto, la articulación de raza, lengua y nación es problemática en el discurso literario panameño porque está ligada a un imaginario nacional que hace hincapié en la panameñidad y, por ende, en la hispanidad.

La retórica nacional del país, junto con el discurso del mestizaje, obstaculizó la conciencia negra y, aún más, marginalizó a los afroantillanos. La ideología nacional no únicamente excluyó a la negritud, sino que también estimuló las tensiones intraétnicas entre los afrocoloniales y los antillanos, una dinámica racial que caracteriza a Panamá. Inevitablemente, las tensiones ideológicas nacionales se manifestaron entre los afrocoloniales y los antillanos. Estas tensiones marcaron la literatura escrita por los panameños negros del siglo XIX hasta la actualidad.

\section{Discurso nacional del siglo XIX}

La historia de los afrocoloniales en Panamá se remonta a la época colonial (1789), cuando los negros libres o esclavos ya comprendían el 63\% de la población panameña (Rout, 2003: 273). La numerosa población de negros descendientes en Panamá contribuyó a que el país adquiriera la reputación de ser una provincia negra en el siglo XIX. La presencia africana incomodó a la oligarquía panameña durante el siglo XIX, especialmente como consecuencia de la Revolución haitiana (17891804) y el levantamiento de los negros esclavos. Como resultado, la numerosa población africana en Panamá influyó en la decisión de la oligarquía de unirse a la Gran Colombia -Colombia, Ecuador, Panamá y Venezuela- después de su independencia en 1821. Simón Bolívar expresó con frecuencia su preocupación por Haití y sus negros rebeldes. Para Bolívar, este era un modelo que los latinoamericanos deberían evitar (Geggus, 2003: 48-49). A pesar de los esfuerzos del país por ocultar su presencia africana, se hizo cada vez más difícil debido a la creciente población de antillanos que emigró a Panamá durante los siglos XIX y XX.

Debido a la creciente población antillana, durante el proyecto de construcción de la identidad nacional panameña (1880-1920) las particularidades raciales dejaron de tener importancia y el discurso intelectual del "mestizaje" permitió concebir una nación unificada basada en sus semejanzas. Como Juan de Castro señala: "The discourse of mestizaje... thus became a way for the three numerically dominant races living in the Americas-white, Amerindian, and black-to become incorporated into the same national project" (2002: 19). Como consecuencia, la clasificación de muchos panameños de ascendencia africana varía entre "mulato", 
"mestizo", "moreno" y "negro", dependiendo de su tez y de la presencia o ausencia de rasgos africanos. A pesar de que el código racial "mulato" generalmente se refiere a la mezcla de blancos y negros, "mestizo" se utiliza comúnmente para designar cualquier combinación de las poblaciones de blancos, indígenas y africanos y, por lo tanto, no toma en cuenta las diferencias raciales. Los códigos raciales "moreno" y "negro" se refieren a las personas de ascendencia africana, pero se diferencian en cuanto a la visibilidad de sus características africanas. La clasificación de una persona de ascendencia africana como "moreno" o "negro" depende de su aproximación a la blancura o la negritud en cuanto a su color y características físicas. Aunque los negros y los hispanos son casi siempre clasificados como "morenos" dependiendo de la presencia o ausencia de rasgos africanos, ellos también pueden ser considerados "negros". Obviamente, el uso de estos códigos raciales sigue siendo ambiguo. En Panamá, la palabra "negro" genera connotaciones negativas que se asocian con la esclavitud, con África y con la población afroantillana. Como resultado, muchos afroantillanos son clasificados como "negros" porque se identifican con sus países natales -Jamaica y Barbados-y hablan inglés. A su vez, para muchos afrocoloniales ser clasificado como negro es un insulto, y los alinea con la población afroantillana denigrada.

\section{El sentimiento anti-afroantillano en Panamá}

Las primeras décadas del siglo XX se caracterizaron por un fuerte sentimiento anti-afroantillano. El texto El peligro antillano en la América (1924) de Olmedo Alfaro articuló este sentimiento y las supuestas diferencias entre los afrocoloniales y afroantillanos.

A este respecto, Alfaro escribió:

Es evidente que hay gran diferencia entre el negro antillano y el hombre de color desarrollado dentro de la civilización indo-americana, no solamente por su status en las vecinas colonias inglesas, donde su situación económica es deprimente y sus salarios ridículos, sino también por el ambiente de respeto de que en nuestras sociedades disfrutan las razas de color, consideraciones que les han sido acordadas por la nobleza de su carácter y su asimilación a nuestras más altas virtudes morales (Alfaro, 1924:7).

En otras palabras, los afrocoloniales eran hispanos, católicos y de habla española, mientras que los afroantillanos eran negros, protestantes y de habla inglesa. La oligarquía panameña promovió la asimilación y los alentaron a renunciar a sus lazos lingüísticos y culturales con sus respectivos países del Caribe para animarlos a salir de Panamá después de la construcción del canal en 1914. A través de las leyes 13 (1926) y 26 (1941) se impidió a los afroantillanos la entrada al país y se les obligó a hablar español para obtener la ciudadanía. Los afroantillanos finalmente lograron la ciudadanía en 1946 con la nueva Constitución (Herzfeld, 1983: 151). Sin embargo, como la Ley 26 ordenó en 1941, la Constitución de 1946 promovió la asimilación cultural, ya que muchos temían que su religión protestante y su lengua nativa - el inglés - alterarían el paradigma cultural de Panamá.

Muchos líderes antillanos creían que el éxito del afroantillano en Panamá dependía de su capacidad de asimilar y adoptar los principios más importantes de la nacionalidad panameña: lengua —español一, cultura - hispana - y religión — catolicismo- Por consiguiente, líderes afroantillanos prominentes, como George Washington Westerman (1910-1988), alentaron a otros afroantillanos a asimilarse con el fin de ser aceptados como panameños. No es de extrañar que Westerman no se enfocara en las diferencias culturales o raciales entre los afroantillanos y los panameños. En cambio, promovió la asimilación y celebró la capacidad intelectual del afroantillano y sus contribuciones económicas a Panamá. Westerman animó a los afroantillanos a educarse y llamó la atención sobre las prácticas abusivas en la zona del canal. A pesar de sus esfuerzos, la discriminación contra el antillano persistió a lo largo del siglo XX y sirvió como principal efecto catalizador en la temática literaria de varios escritores antillanos contemporáneos. ${ }^{2}$ Además, esta discriminación racial se manifestó en las obras de los primeros escritores negros que publicaron en el istmo 
de Panamá, en las que negaban su propia negritud. Esta temática caracteriza la obra de uno de los escritores negros más famosos de Panamá, que niega su propia negritud a favor de una estética blanca europea.

El color de la piel presentó un problema para los poetas afrocoloniales decimonónicos. José Dolores Urriola (1834-1883) fue un escritor de la lucha del siglo XIX por la Independencia y perteneció a la primera generación de escritores románticos en Panamá. ${ }^{3}$ Conocido como "el mulato Urriola", era un poeta romántico en cuya poesía trató temas políticos de la época. Urriola participó en los movimientos políticos durante ese período y se desempeñó como secretario del Jurado Civil en 1861 (Miró, 1966: 35). Conocido por su verso epigramático, la poesía de Urriola fue a la vez popular y satírica y caracterizó numerosos problemas del siglo XIX, como el deseo del país de liberarse de la Gran Colombia. A pesar de que sus poemas fueron pocos en número, siguen dándonos una idea de las obras de un poeta negro que escribió durante el proyecto de construcción de la nación y que excluyó problemas de identidad racial.

Su poema "Sátira contra el general Mosquera" es un ejemplo de su verso epigramático por su ingenio y tono ligero. Aquí, Urriola satiriza a una figura política, Tomás Cipriano de Mosquera (1798-1878), quien se desempeñó en diferentes momentos históricos como presidente de la Gran Colombia entre 1845 y 1867. Mosquera fue un presidente eficaz, pero era conocido por ser dominante, violento y emocional y, por lo tanto, fue a la vez reverenciado y temido por los ciudadanos de Panamá. Como resultado, Urriola retrató a Mosquera como un tirano despiadado. Según explica:

¿Quién más malo que Caín, que Judas y Barrabás?

Tomás.

¿Quién más sangriento y tirano que Nerón y Diocleciano?

Cipriano.

Sangre y luto por doquiera

marca tu fatal carrera, Mosquera.
Más humana es la pantera,

el tigre menos feroz;

nadie, nadie es peor que vos

Tomás Cipriano Mosquera.

(Miró, 1966: 36)

Urriola deshumanizó a Mosquera al compararlo con las figuras más despiadadas de la historia bíblica, como los tiranos romanos y los animales voraces. Con su sátira envió un mensaje político a un país que deseaba separarse de la Gran Colombia. Este autor utilizó la poesía para atacar, criticar y satirizar a los políticos, de modo que se comprometieran con el proyecto nacionalista de Panamá. Asimismo, Urriola reconoció la posición marginal de su país como miembro de la Gran Colombia porque después de unirse a ella, Panamá expresó descontento con las políticas del gobierno de Colombia ya que este país no reconoció el potencial económico de la posición geográfica de Panamá (Szok, 2001: 38).

Aunque fue conocido como "el mulato", José Dolores Urriola escribió sobre los problemas políticos de su momento, en lugar de sobre su raza, de modo que escogió su país sobre su raza. Por otra parte, Urriola exhibió el orgullo nacional inherente a esta generación de poetas afrocoloniales. Curiosamente, la identificación del poeta como mulato no se manifestó como una conciencia racial en sus obras. Como primer escritor de ascendencia africana que publicó poemas en Panamá, al igual que otros escritores románticos de la época, Urriola se sintió obligado a emular el estilo literario de la época y, como mulato, tuvo que esconder sus raíces africanas para formar parte de la nación panameña. Aunque se supone que esta identificación era normal en la época, la ausencia del tema de la negritud es tan importante como su presencia porque señala el ambiente racial de la época. Muchos escritores no sentían la libertad de expresar su negritud en la poesía, y tampoco había muchos modelos para emular durante esta época dentro o fuera del país. ${ }^{4}$

El poeta afrocolonial decimonónico Gaspar Octavio Hernández también promovió la nacionalidad sobre la raza. Hernández es un poeta muy conocido en Panamá 
por su poema de nacionalidad "Canto a la bandera" (1916). Su obra está recogida en la antología Cien años de poesía en Panamá (1966) y es considerado un poeta modernista que escribió sobre la Independencia. En la plaza de Santa Ana, en la ciudad de Panamá, hay un monumento que conmemora su vida, su poesía y su muerte de tuberculosis a una edad temprana - veinticinco años-. Sin embargo, Hernández también fue un poeta que luchó con su identidad africana. En su poema "Ego sum”, Hernández elevó la blancura sobre la negritud, una característica común en la poesía escrita por poetas afrolatinoamericanos del siglo XIX. ${ }^{5}$ En la estrofa inicial, Hernández se describe a sí mismo por primera vez en términos de lo que no es:

\section{Ni tez de nácar, ni cabellos de oro veréis ornar de galas mi figura; ni la luz del afir, celeste y pura, veréis que en mis pupilas atesoro. (Miró, 1966: 187)}

Las palabras "luz del afir", "celeste" y "pura", que evocan belleza y pureza, contrastan dramáticamente con la siguiente estrofa, en la que el poeta describe con fatalismo quién es en realidad: un hombre negro con rasgos negroides africanos.

Con piel tostada de atezado moro; con ojos negros de fatal negrura, del Ancón a la falda verde oscura nací frente al Pacífico sonoro.

(Miró, 1966: 187)

Hernández se describe a sí mismo no sólo como negro, sino con una negrura fatal. Establece la dicotomía entre lo blanco y lo negro usando imágenes de blancura - luz del afir, celeste, pura - y negritud - piel tostada, ojos negros, fatal negrura- A pesar de que se identifica como negro en este poema, lo hace en un segundo lugar y en relación con no ser blanco.

Como escritor negro durante el apogeo de la construcción de la identidad nacional panameña (18801920), Hernández luchó con su negritud y le fue difícil definirse y distinguirse en una nación que no aceptó la negritud inherente al país. Cuando Hernández escribió "Ego sum" en 1916, era difícil ser negro y panameño, y no existía un discurso literario para hablar de la negritud en Panamá y, por ende, en América Latina. Con la excepción de su contemporáneo literario Federico Escobar (1861-1912), quien declaró su propia negritud en el poema "Nieblas" en 1891, ningún otro poeta africano en Panamá había declarado su negritud. Tampoco había un lugar en los círculos literarios para que los escritores negros se definieran durante esa época. Aunque Hernández fue conocido como "el cisne negro", esa identificación estaba separada de las realidades del negro de la época: la discriminación, la falta de educación y la pobreza.

Por otra parte, Hernández destacó el sentimiento anti-afroantillano por no ser lo suficientemente hispano. En su ensayo "El culto del idioma", Hernández expresó desdén por los antillanos que se negaban a aprender o hablar español, a la vez que los criticó por tratar de ser estadounidenses en lugar de panameños debido a sus vínculos con el canal. Hernández distinguió a los antillanos de los afrocoloniales basándose en diferencias lingüísticas y culturales. En "El culto del idioma", Hernández argumentaba que los antillanos "se pirran por norteamericanizarse [...] prescinden descaradamente de su lengua materna y su afán de expresarse a menudo en su incomprensible y tosco dialecto anglo-yanqui" (Hernández, 1916:112). Hernández demostró que el sentimiento anti-afroantillano estaba vinculado con el sentimiento nacional antiimperialista y antiyanqui dirigido a Estados Unidos. Debido a que muchos antillanos hablaban inglés, los panameños los veían como una amenaza a la imagen nacional hispana que querían propagar. Es decir, la oligarquía panameña de entonces quería propagar una imagen de un país con hispanos que hablaban español.

Durante la época de la construcción de la nación panameña, los panameños trataron de reconstruir su imagen con base en sus raíces hispanas. Por ejemplo, cambiaron el nombre oficial de su moneda a "balboa" en referencia al conquistador español del país, Vasco Núñez de Balboa (1475-1519), para reforzar sus raíces 
hispanas (Szok, 2001: 99). De acuerdo con Benedict Anderson en Imagined Communities, la nación es una comunidad política construida e imaginada (Anderson, 1991: 6). Por lo tanto, muchos antillanos de habla inglesa, que componían la mayoría de los inmigrantes caribeños, fueron percibidos como aliados de Estados Unidos y no reflejaban la imagen nacional construida por la oligarquía panameña. La imagen hispana, y por ende blanca, que los nacionalistas deseaban propagar, no incluía al inmigrante afroantillano, cuya presencia trastornaba a la oligarquía.

\section{La literatura afroantillana en Panamá}

Carlos Cubena Guillermo Wilson (1941-), poeta, cuentista y novelista contemporáneo afropanameño de descendencia antillana, reaccionó a este sentimiento nacional anti-afroantillano en su literatura. Wilson es el escritor más conocido de ascendencia africana de Panamá y fue uno de los primeros en reaccionar en contra de la discriminación abierta de la nación contra los negros. La ficción y la poesía de Wilson revelan las tensiones intraétnicas entre los afrocoloniales y los afroantillanos, y conserva la herencia antillana en Panamá mediante la divulgación de años de prejuicios contra la comunidad antillana en el istmo.

En Raíces africanas: los mosquitos de orixá Changóo (2005), Wilson denuncia la discriminación racial diaspórica que afecta a los afrodescendientes. En su poema "Iratus" denuncia específicamente la discriminación nacional hacia el afroantillano panameño.

\author{
Mi primer grito en esta vida \\ fue protesta a la injusticia \\ 5 lustros sin ciudadanía \\ 5 lustros \\ $\sin$ \\ ciudadanía \\ 5 \\ ¿Mi delito? \\ La ascendencia afroantillana. \\ ¿Mi pecado? \\ La herencia chomba.
}

\author{
5 lustros sin ciudadanía. \\ 5 lustros \\ $\sin$ \\ ciudadanía \\ 5 \\ [...] (Wilson, 2005: 118)
}

El verso "5 lustros sin ciudadanía" refleja los veinticinco años que a los afroantillanos se les negó la ciudadanía por su color - negro-y su lengua - elinglés-. La Ley 13 de 1926 y la Ley 26 de 1941 impidieron a los antillanos la entrada al país y les obligaron a hablar español si querían obtener la ciudadanía, la cual finalmente lograron en 1946 bajo la nueva Constitución (Herzfeld, 1983: 151). El verso corre por el poema y se repite diez veces para anunciar el rencor que la voz poética tiene por su patria. La voz poética señala que la gran ironía es que ha experimentado mejor trato en Estados Unidos, un país que tiene una historia peor de racismo contra los afrodescendientes:

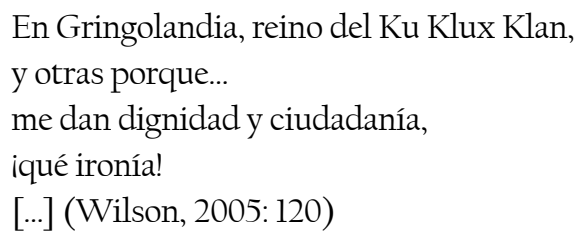

Su único delito es ser afroantillano. Estos cinco lustros representan el rechazo y la negación que en el istmo se observa por el sector minoritario de su país. Este poema, junto con otros de su colección, advierte sobre la denuncia del racismo panameño que impregna su trilogía: Chombo (1981), Losnietos de Felicidad Dolores (1991) y La misión secreta (2005).

En su novela didáctica Los nietos de Felicidad Dolores (1991) reacciona ante las injusticias contra los antillanos y explora las tensiones intraétnicas entre afrocoloniales y afroantillanos. La novela comienza en el futuro, en 1999, año en que se firmaron los tratados TorrijosCarter, ${ }^{7}$ con los que Estados Unidos devolvió el control del canal a Panamá. Como sugiere el título, la novela se enfoca en los descendientes de Felicidad Dolores, que son similares a pesar de sus diferencias de origen, 
culturales y lingüísticas. La narración comienza en un aeropuerto de Estados Unidos, donde los descendientes de los afroantillanos se reúnen para regresar al istmo con el fin de atestiguar la transferencia de la operación del canal de Estados Unidos a Panamá. La novela trata de los prejuicios de dos familias, la de Juan Moreno y la de John Brown, que son afrocoloniales y afroantillanos, respectivamente. A lo largo de la novela, los personajes intentan descifrar el significado de la palabra "sodinu", que es "unidos" escrito al revés. Debido a la fragmentación cultural de los personajes, no son capaces de descifrar el significado de la palabra. En cambio, Wilson, el autor, se inserta a sí mismo en el texto y explica el significado de la palabra en una carta en la que relata que los afrolatinoamericanos están "unidos" por su herencia común africana. Wilson señala la herencia común de los afrocoloniales y los antillanos, que tiene sus raíces en un pasado lejano. El parecido físico de los patriarcas de la novela, John Brown y Juan Moreno, también refuerza su herencia africana común y señala lo absurdo de una posible unión.

Pero el día en que Juan Moreno se encontró, cara a cara, con John Brown, como quien se espanta de su propia sombra (además del parecido físico y los mismos gestos y ademanes, ambos tenían pantalón remendado, estafadores parches de diferentes colores sobre tela de y, curiosamente, del mismo estilo de costura) [...]. (Wilson, 1991: 120-21)

A pesar de sus diferencias culturales, los afrocoloniales y los antillanos en Panamá son claramente más similares que diferentes, lo que constituye el mensaje principal de Wilson. En la segunda sección de Losnietos, el narrador pone de manifiesto que los antillanos son descendientes de los negros en España, lo cual subraya su conexión con los afrocoloniales en Panamá. Estas diferencias son menos reales para la generación actual de descendientes negros. En Los nietos deja claro que muchos afrocoloniales y afroantillanos buscan unirse a pesar de las disputas de sus antepasados. Por ejemplo, los hijos respectivos de Brown y Moreno, Salvadora y Aníbal, desean tener una relación romántica a pesar de la prohibición de sus padres, de modo que siguen una relación a escondidas, lo que refleja una lucha generacional.

Melva Lowe de Goodin (1945) es otra escritora afroantillana de Panamá y es una de las pocas escritoras afropanameñas. Lowe de Goodin tuvo fama con la publicación de su única obra literaria, De/From Barbados a/to Panamá (1999), una obra de teatro bilingüe e histórica en la que simultáneamente se traza la historia de los trabajadores del canal de Panamá (1904-1914) que se trasladaron de Barbados a Panamá y su lucha por integrarse en un país foráneo. Varios críticos ya han hablado de la importancia de esta obra y cómo representa la memoria colectiva y común de los afroantillanos (Nwankwo), la recuperación/representación de la identidad de los afroantillanos a través del lenguaje (Watson) y el papel del performance en la obra (Zien). Esta obra reinterpreta la llegada de los afroantillanos de Barbados a Panamá a través de la memoria, la historia y la voz colectiva del pueblo. El interés de Lowe de Goodin por recuperar la historia de los barbadenses durante su llegada a Panamá en 1909 le guió a explorar la historia de todos los descendientes africanos en Panamá. Su publicación más reciente, Afrodescendientes en el Istmo de Panamá (1501-2012) (2012), es una compilación histórica de los aportes de los descendientes africanos en Panamá desde la época precolonial hasta hoy. Aunque la mayor parte de la obra rescata voces y figuras masculinas de ascendencia africana en Panamá, la autora dedica un capítulo a la mujer afropanameña, en el que muestra a la vez el aporte de las mujeres afropanameñas al país y la escasez de información sobre ellas debido a su género y raza. El cuarto capítulo de la compilación, "La mujer afropanameña", se dedica a la mujer afropamaneña en la época colonial. Un caso interesante es el de la mulata Tomasa Pardo, una mujer libre y rica que durante el siglo XVIII negoció con esclavos, alhajas y fincas durante la época de la esclavitud (Lowe de Goodin, 2012: 67). Este caso es interesante porque se sabe poco de ella y trae a la luz los variados papeles que desempeñaron mujeres y esclavos durante la época de la esclavitud. Muestra cómo la mujer afro tomó ventaja del sistema de esclavitud para destacarse y adelantarse económica y socialmente. No fue únicamente víctima. 
Por otro lado, Lowe de Goodin rescata la explotación de la mujer afroantillana durante la construcción del canal de Panamá. Esta perspectiva de la mujer afroantillana como trabajadora refuta la visión exclusivamente masculina de los trabajadores que emigraron primordialmente de Barbados y Jamaica para trabajar en el canal. Las mujeres que emigraron a Panamá durante la construcción del canal francés (18811889) y el canal americano (1904-1914) desempeñaron principalmente los siguientes papeles: esposas y jefas de familia, vendedoras ambulantes, prostitutas, lavanderas, servicio doméstico y mujeres que ofrecían hospedaje o dueñas de hoteles (Lowe de Goodin, 2012: 74). Es decir, la mujer afroantillana también desempeñó un papel importante durante la construcción del canal y, como consecuencia, en la creación de la nación panameña moderna. Este trabajo de Lowe de Goodin une los logros de afrocoloniales y afroantillanos, y resalta la importancia de la mujer en la construcción de la nación panameña desde la época precolonial hasta la actualidad. En este sentido, Lowe de Goodin rescata del olvido al descendiente africano y particularmente a la mujer afro, que fue invisibilizada por la historia. En la ficción y recopilación histórica de Lowe de Goodin, las mujeres de ascendencia africana en Panamá — sea afrocolonial o afroantillana- se unen por su deseo de destacar como individuos y de tener una voz propia.

La literatura de Juan Urriola, Gaspar Octavio Hernández, Carlos Cubena Guillermo Wilson y Melva Lowe de Goodin refleja que la unión de la identidad afropanameña sigue siendo complicada por la percepción de la identidad cultural, racial y nacional que resulta a causa de las ideologías propiciadas por el mestizaje y la negritud. La identidad negra en Panamá es compleja y está comprendida por múltiples identidades que reflejan la hibridez de la experiencia de la diáspora africana. Sin embargo, esta hibridez se basa en un origen común - África - que ha unido a los afrodescendientes desde África a las Américas. La identidad afropanameña no es singular, sino que está compuesta de varias identidades transformadas por la esclavitud, el mestizaje y la inmigración. Los negros descendientes en Panamá son el producto de África,
Jamaica, Barbados y otros países caribeños - Trinidad, Martinica, Guadalupe, etcétera-, que se entrelazaron para formar el Panamá contemporáneo. Esta identidad multifacética e híbrida es el producto de la experiencia de la diáspora africana.

¿Qué significa ser afropanameño en el nuevo milenio? ¿Cuáles son los logros de la comunidad afropanameña? ¿Hay esperanza para el futuro? La articulación de una identidad unida afropanameña en el nuevo milenio requiere de una reconciliación de la identidad africana que tome en cuenta la historia del pasado, el presente y el futuro. El gobierno del país ha avanzado mucho en el reconocimiento de los afrodescendientes. Por ejemplo, en 2000 el país estableció el 30 de mayo como el Día de la Etnia Negra, un día feriado nacional en el que se celebra la etnicidad de los afrodescendientes. Sin embargo, la invisibilización del negro continúa.

Según el abogado y activista Alberto Barrow, esta invisibilización nacional sale a la luz en el censo de Panamá 2010, que reviste una especial importancia dado que por primera vez después de setenta años se incluyó una pregunta sobre las raíces africanas. A pesar de este logro, el censo nacional cometió varios errores. Según Barrow, más de setecientas mil personas no fueron censadas, porque de la población total -3.8 millones-, a más del 60\% de las personas no se les preguntó sobre la raza: "En este hogar hay alguien que se considera negro(a) o afrodescendiente"? (Barrow, 2012: 52). Por este motivo, únicamente el 9\% de la población total se identificó como afrodescendiente, a pesar de que se cree que el 33\% de la población tiene raíces africanas. Esta omisión o exclusión no rompió la invisibilización nacional del negro descendiente y continuó reforzando el estereotipo erróneo de que son pocos los descendientes de negros.

\section{Notas}

${ }^{1}$ Es de notar que la primera oleada de inmigración afroantillana a Panamá comenzó en 1850 para la construcción del ferrocarril transístmico. Con esta oleada, más de 45000 afroantillanos emigraron de Jamaica para participar en la construcción. Cuando 
los franceses comenzaron el proyecto, que fracasó en 1880, trajeron a 84000 jamaiquinos al país. Cuando Estados Unidos tomó el control del proyecto en 1903, este país trajo aproximadamente 19900 trabajadores de Barbados para completar el proyecto que hoy conocemos como Canal de Panamá. Además, mientras que la mayoría de los afroantillanos emigró de Jamaica y Barbados, una minoría de antillanos lo hizo de los países francófonos de Trinidad, Martinica y Guadalupe.

${ }^{2}$ En este grupo se encontraban Melva Lowe de Goodin (1945), Gerardo Maloney (1945), Carlos E. Russell (1934) y Carlos Guillermo Wilson (1941), autores que se han dedicado a escribir sobre la discriminación del afroantillano en Panamá y sobre la problemática de la identidad. Sus obras señalan el carácter híbrido de la comunidad y sus desafíos de identificarse como panameños, caribeños o negros, en un país que niega sus raíces africanas.

${ }^{3}$ Los poetas románticos en Panamá fueron la primera generación literaria en Panamá -aunque no los primeros escritores- y participaron en los movimientos politicos de la época (Levi, 1989: 20). Los escritos de los poetas románticos "panameños" ilustran el creciente espíritu nacionalista en el istmo de Panamá. Por ejemplo, el poeta romántico Gil Colunje (1831-1899), un representante de la primera generación de escritores románticos, escribió su propio canto a la Independencia de Panamá de España, titulado " 28 de noviembre" (1852), un poema en el que elogiaba a su país y a Bolívar (García, 1964: 41). Juan Urriola forma parte de esta generación y tradición.

${ }^{4}$ Es de notar que el poeta afrocolombiano Candelario Obeso (1849-1884) fue uno de los pocos escritores de ascendencia africana que publicó y escribió sobre el dolor de ser negro.

${ }^{5}$ Para más información sobre este tema, véase Piedra (1987)

${ }^{6}$ Raíces africanas (2005) es una compilación de los siguientes cuentos y poemas: Cuentos del negro Cubena: pensamiento afro-panameño (1977) y Pensamientos del negro Cubena: pensamiento afro-panameño (1977).

${ }^{7}$ Los tratados Torrijos-Carter, firmados en 1977 por el presidente Jimmy Carter (Estados Unidos) y el general Omar Torrijos (Panamá), aseguraron que Panamá tomaría el control y la operación del canal a partir de 1999.

\section{Referencias bibliográficas}

Alfaro, Olmedo (1924), El peligro antillano en la América Central. Panamá: Imprenta Nacional.

Anderson, Benedict (1991), Imagined Communities: Reflections on the Origin and Spread of Nationalism. Londres/Nueva York: Verso.

Barrow, Alberto N. (2012), La variable étnica en el marco legal de Panamá. Panamá: Editorial Fuga.

Castro, Juan de (2002), Mestizo Nations: Culture, Race and Conformity in Latin American Literature. Tucson: University of Arizona Press.

García S., Ismael (1964), Historia de la literatura panameña. México: UNAM.

Geggus, David (2003), "The Influence of the Haitian Revolution in Blacksin Latin America and the Caribbean". En Nancy Priscilla Naro (ed.), Blacks, Coloureds and National Identity in Nineteenth-Century Latin America. Londres: Institute of Latin American Studies, pp. 38-59.

Hall, Stuart (1989), "Cultural Identity and Diaspora”. En Framework, núm. 36, pp. 222-237.

Hernández, Gaspar Octavio (1916), Iconografía. Panamá: Imprenta Esto y Aquello.

Herzfeld, Anita (1983), "The Creoles of Costa Rica and Panama”. En John Holm (ed.), Central American English. Heidelberg: Groos, pp. 131-55.

Jaramillo Levi, Enrique (ed.) (1991), When New Flowers Bloomed: Short Stories by Women Writers from Costa Rica and Panama. Pittsburgh: Latin American Literary Review Press.

Lowe de Goodin, Melva (2012), Afrodescendientes en el Istmo de Panamá (1501-2012). Panamá: Editora Sibauste.

Miró, Rodrigo (1966), Cien años de poesía en Panamá (18581952). Panamá: Librería Avance.

Nwankwo, Ifeoma C.K. (2002), "The Art of Memory in Panamanian West Indian Discourse: Melva Lowe de Goodin's De/From Barbados a/to Panama". En Palara, núm. 6, pp. 3-17. 
Piedra, José (1987), "Literary Whiteness and the AfroHispanic Difference". En New Literary History, núm. 18, pp. 303-332.

Rout, Leslie B. (2003), The African Experience in Spanish America. Princeton: Markus Wiener Publishers.

Szok, Peter A. (2001), "La últimagaviota:" Liberalism and Nostalgia in Early Twentieth-Century Panamá. Connecticut: Greenwood.

Watson, Sonja Stephenson (2005), "The Use of Language in Melva Lowe de Goodin's De/From Barbados a/to Panamá: A Construction of Panamanian West Indian
Identity”. En College Language Association Journal, vol. 49, núm. 1, pp. 28-44.

Wilson, Carlos Guillermo (1991), Los nietos de Felicidad Dolores. Miami: Universal Editions.

Wilson, Carlos Guillermo (2005), Raíces africanas: los mosquitos de orixá Changó. Panamá: Book Surge.

Zien, Katherine (2009), "Toward a Pedagogy of Redress: Staging West Indian Panamanian History in De/From Barbados a/to Panamá". En Latin American and Caribbean Ethnic Studies, vol. 4, núm. 3, noviembre, pp. 293-317. 